\title{
OBTENÇÃO DE CARVÃO ATIVADO IMPREGNADO COM ÍONS METÁLICOS PARA FINS BACTERICIDAS
}

\author{
RIBEIRO, G.V. ${ }^{1}$, RIGO, C. ${ }^{1}$, VARGAS, A.C. ${ }^{2}$, GRESSLER, L. T. ${ }^{2}$, FOLETTO, E.L. ${ }^{1}$ \\ ${ }^{1}$ Universidade Federal de Santa Maria, Programa de Pós-graduação em Engenharia de Processos \\ ${ }^{2}$ Universidade Federal de Santa Maria, Departamento de Medicina Veterinária Preventiva \\ E-mail para contato: gvieiraribeiro@gmail.com
}

\begin{abstract}
RESUMO - O desenvolvimento de produtos com ação antimicrobiana, inibitória ou mesmo letal, tem atraído considerável atenção nos mais distintos campos de pesquisa e aplicações. O objetivo deste estudo é obter um material antimicrobiano a partir de carvão ativado submetido à adsorção em um meio com íons metálicos. Para a caracterização deste material, avaliaram-se os efeitos inibitório e bactericida das amostras através de testes microbiológicos com diferentes bactérias. Quanto à metodologia experimental aplicada, foram testados os efeitos da presença de íons de prata, de cobre e de zinco, através de amostras de carvão impregnado em culturas de bactérias Escherichia coli e Staphylococcus aureus de diferentes cepas. Tais efeitos foram avaliados através de testes de concentração mínima inibitória e concentração mínima bactericida.
\end{abstract}

\section{INTRODUÇÃO}

\subsection{Contexto}

O desenvolvimento de produtos com ação antimicrobiana, inibitória ou mesmo letal, tem atraído atenção em diferentes campos de pesquisa e aplicações. Quer sejam empregados em ambientes industriais, hospitalares, sanitários ou mesmo domiciliares, esses chamados biomateriais atuam de forma eficaz na prevenção, no controle e no combate a agentes microbiológicos nocivos e às patogenias por eles desencadeadas.

Segundo Morones et al. (2005), surtos de doenças infecciosas causadas por diferentes bactérias patogênicas e o desenvolvimento de resistência aos antibióticos são alguns dos fatores que desencadeiam a procura por novos agentes antibacterianos.

Ainda que alguns materiais conhecidos naturalmente ofereçam esse efeito antimicrobiano, cabe ao segmento de pesquisa e desenvolvimento de materiais, encontrar através de novas fontes e adequando tecnologias aos diferentes processos, produtos que atendam às demandas específicas que surgem constantemente, intensificando propriedades inerentes ao material originário sem 
alterar demais características desejáveis. Nessa linha de pesquisa, a preparação de sólidos com propriedades inibitórias ou bactericidas, através da metodologia de impregnação de íons metálicos, é fonte de diversos estudos.

Li et al.(2002) aponta que vários compostos apresentam um conhecido efeito microbicida, especialmente os de natureza orgânica. Contudo, o uso deste tipo de compostos apresenta desvantagens como tendências de volatilização ou decomposição, pontos de fusão e ebulição baixos, além de apresentarem alguma toxidade.

Hu (HU,2000, apud Li et al., 2002) comenta que os materiais inorgânicos dotados desse efeito normalmente ocorrem sob a forma de compósitos onde a incorporação de íons metálicos ou compostos orgânicos dentro ou fora de suas estruturas os faz atuar como um carregador ou um suporte que libera estas substâncias de forma controlada e apropriada. Entre os carregadores inorgânicos citados com maior frequência na literatura, incluem-se, zeólitas, argilas, vidro e carvão ativado.

Como exemplos de produtos aos quais se agregam esses agentes, podem-se citar filtros de tratamento de águas de abastecimento, cerâmicas e descontaminantes para pisos (utilizáveis em ambientes assépticos), bandagens para queimaduras e materiais para implantes ósseos, aditivos nas rações animais, na produção de tintas e na de papéis, entre outros.

O objetivo dessa pesquisa é obter e caracterizar um material antimicrobiano a partir de carvão ativado submetido à adsorção em um meio com íons metálicos. Optou-se primeiramente pela aplicação da prata, que, como citado por Park \& Jang (2003), tem um longo histórico de uso medicinal como agente antimicrobiano e, posteriormente, testaram-se amostras contendo zinco e cobre, metais recorrentemente apontados no levantamento bibliográfico realizado.

\section{METODOLOGIA}

\subsection{Referencial Teórico}

Trata-se de uma metodologia de pesquisa experimental aliada à pesquisa bibliográfica e documental. Para tal, os dados referenciais foram coletados mediante diferentes fontes, nas quais se destacaram publicações periódicas, dissertações, teses e patentes, enquanto que os dados experimentais foram obtidos em ambiente laboratorial.

\subsection{Metodologia Experimental}

A obtenção das amostras de carvão ativado impregnado com íons metálicos foi dividida em três etapas, aqui descritas como experimento I, experimento II e experimento III.

$\mathrm{O}$ experimento I consistiu em um pré-teste, nele produziram-se quatro amostras de diferentes concentrações de prata que foram submetidas apenas a teste microbiológico de disco-difusão em ágar. Com base nos resultados obtidos nessa primeira etapa, o experimento II foi conduzido com novos limites de trabalho. Um terceiro experimento, citado como experimento III, foi realizado empregando- 
se a mesma metodologia do experimento II, mas também com íons metálicos de cobre e de zinco e um tratamento térmico adicional.

\subsubsection{Experimento I}

Nesta etapa foram preparadas quatro amostras inicias de carvão impregnado com prata. As concentrações de prata desejadas eram de $0.5 \%, 1.0 \%, 2.0 \%$ e $5.0 \%$ (onde o percentual refere-se à proporção em peso de $\left.\mathrm{g}_{\text {prata }} / \mathrm{g}_{\text {carvãoimpregnado }}\right)$.

Para a preparação da suspensão base, $100 \mathrm{~mL}$ de água deionizada foram vertidos sobre 5,0 gramas de carvão ativado pulverizado, previamente seco em estufa à temperatura aproximada de $100^{\circ} \mathrm{C}$. Preparam-se quatro suspensões que foram mantidas, em erlenmeyers de vidro de $250 \mathrm{~mL}$, sob agitação de 110 rpm, em incubadora shaker.

As quatro soluções de $\mathrm{AgNO}_{3}$ necessárias foram preparadas de acordo com a Tabela 1, com água deionizada, em balões volumétricos de $50 \mathrm{~mL}$. Uma vez preparadas as soluções de nitrato de prata, com o auxílio de uma pipeta volumétrica de $50 \mathrm{~mL}$, cada uma foi gotejada lentamente sob a sua respectiva suspensão em agitação. A adsorção foi então conduzida, ainda sob agitação de $110 \mathrm{rpm}$ e temperatura de $30^{\circ} \mathrm{C}$, durante duas horas.

Tabela 1- Soluções de $\mathrm{AgNO}_{3}$.

\begin{tabular}{|c|c|c|c|c|}
\hline Solução & $\begin{array}{c}\text { Fração de } \\
\text { prata (\%) }\end{array}$ & $\begin{array}{c}\text { Massa de carvão } \\
\text { impregnado (g) }\end{array}$ & Massa de Ag (g) & $\begin{array}{c}\text { Massa de } \\
\text { AgNO }_{\mathbf{3}} \text { (g) }\end{array}$ \\
\hline 01 & 0,5 & 5,025 & 0,251 & 0,039 \\
\hline 02 & 1,0 & 5,05 & 0,051 & 0,080 \\
\hline 03 & 2,0 & 5,10 & 0,102 & 0,161 \\
\hline 04 & 5,0 & 5,26 & 0,263 & 0,414 \\
\hline
\end{tabular}

Para se evitarem maiores perdas de massa através da filtração, optou-se por secar, em estufa, à temperatura de $100^{\circ} \mathrm{C}$, durante 90 horas, toda a suspensão após a adsorção. Para facilitar a remoção posterior do sólido, os volumes foram transferidos para béqueres de vidro de $500 \mathrm{~mL}$, onde se adicionaram mais $100 \mathrm{~mL}$ de água deionizada, empregada na remoção do carvão aderido nas paredes dos erlenmeyers.

Ao término do procedimento, possuíam-se quatro amostras de carvão impregnado com prata em diferentes concentrações de $0.5 \%, 1.0 \%, 2.0 \%$ e $5.0 \%$ (em $g_{\text {prata }} / g_{\text {carvãoimpregnado }}$ ). Essas amostras foram então submetidas a teste de disco-difusão em ágar e caracterizaram o pré-teste.

\subsubsection{Experimento II}

Em função dos resultados obtidos no pré-teste, preparou-se nova amostra com a concentração desejada de 2,0\%, onde o percentual refere-se à proporção em peso de $\mathrm{g}_{\text {prata }} / \mathrm{g}_{\text {carvãoimpregnado. }}$

A metodologia de preparo dessa amostra foi similar à descrita no item 2.2.1 (Experimento I). Contudo, em função da quantidade de amostra necessária para a realização dos testes de 
caracterização, partiu-se agora de 10 gramas de carvão ativado pulverizado, previamente seco em estufa à temperatura aproximada de $100^{\circ} \mathrm{C}$. Em termos de novo volume, foram empregados 150 $\mathrm{mL}$ de água deionizada na suspensão, $50 \mathrm{~mL}$ de solução de $\mathrm{AgNO}_{3}\left(0,321 \mathrm{~g}\right.$ de $\left.\mathrm{AgNO}_{3}\right)$ e $50 \mathrm{~mL}$ de água deionizada para auxílio na transferência de frascos. Por se tratar de uma massa maior de sólido, a adsorção foi conduzida a $170 \mathrm{rpm}$. As demais condições se mantiveram constantes.

\subsubsection{Experimento III}

O terceiro experimento foi realizado seguindo-se a mesma metodologia aplicada no experimento II, com as seguintes condições:

- Suspensão- (200 mL de água deionizada e 9,8 gramas de carvão ativado pulverizado previamente seco em estufa à temperatura aproximada de $100^{\circ} \mathrm{C}$ );

- Soluções- (tabela 2 e água deionizada em balão volumétrico de $250 \mathrm{~mL}$ );

- Adsorção- (suspensão mais $60 \mathrm{~mL}$ de solução gotejada)- adsorção conduzida, sob agitação de 110 rpm e temperatura de $30^{\circ} \mathrm{C}$, durante 2 horas.

- Secagem- toda a suspensão + $20 \mathrm{~mL}$ de água deionizada (transferência do sólido), secagem em estufa, à temperatura de $100^{\circ} \mathrm{C}$, durante 90 horas.

Tabela 2- Soluções fontes de Prata, Cobre e Zinco.

\begin{tabular}{|l|c|c|c|c|c|}
\hline Metal & Reagente & $\begin{array}{c}\text { Fração de } \\
\text { metal (\%) }\end{array}$ & $\begin{array}{c}\text { Massa de carvão } \\
\text { impregnado (g) }\end{array}$ & $\begin{array}{c}\text { Massa de metal } \\
\text { (g) }\end{array}$ & $\begin{array}{c}\text { Massa de } \\
\text { reagente (g) }\end{array}$ \\
\hline Prata & $\mathrm{AgNO}_{3}$ & 2,0 & 10,00 & 0,2 & 0,039 \\
\hline Cobre & $\mathrm{Cu}\left(\mathrm{NO}_{3}\right)_{2} \cdot 3 \mathrm{H}_{2} \mathrm{O}$ & 2,0 & 10,00 & 0,2 & 0,080 \\
\hline $\mathrm{Zinco}$ & $\mathrm{Zn}\left(\mathrm{NO}_{3}\right)_{2} \cdot 6 \mathrm{H}_{2} \mathrm{O}$ & 2,0 & 10,00 & 0,2 & 0,161 \\
\hline
\end{tabular}

Uma vez que a atividade de prata e dos demais metais já é conhecida na literatura científica, optou-se pela realização de um tratamento térmico adicional, como apontado nos trabalhos de Oya et al. (1993), Oya e Kimura (1994), Li et al (1998), Adhoum \& Monser (2002), Xavier (2010) e Ko (2010). Após a secagem, as amostras foram submetidas a aquecimento de $400{ }^{\circ} \mathrm{C}$, durante 2 horas, em atmosfera de $\mathrm{N}_{2}$ a uma taxa de aquecimento de $10^{\circ} \mathrm{C} / \mathrm{min}$. Posteriormente, as amostras foram lavadas com $100 \mathrm{~mL}$ de água em filtro de membranas e secas em estufa à $100^{\circ} \mathrm{C}$ durante 48 horas.

\subsubsection{Testes Microbiológicos}

No Experimento I, foram realizados apenas os testes da amostra de carvão ativado impregnado com prata a 2,0\% em meio com as bactérias Staphylococcus aureus ATCC e Escherichia coli ATCC. A figura 1 ilustra o procedimento. Empregou-se a técnica utilizada por Rosário (2010), adaptando-a as amostras de carvão. Foram depositados $2 \mathrm{mg}$ de carvão ativado impregnado com prata em orifícios de $7 \mathrm{~mm}$ de diâmetro no ágar e também papel filtro impregnado com suspensão de $2 \mathrm{mg}$ de carvão e $10 \mu \mathrm{L}$ de água destilada estéril, similar a discos de ATB. 


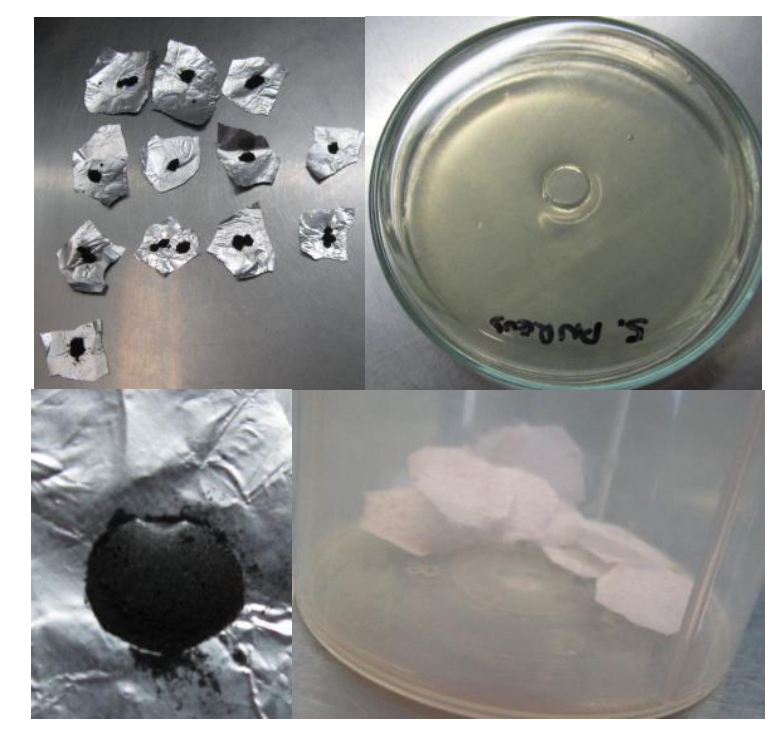

Figura 1- Preparo da amostra para disco-difusão em ágar.

Uma vez obtidas as amostras com a concentração indicada pelo teste de disco-difusão em ágar, realizaram-se análises quantitativas de Concentração Mínima Inibitória (CIM) e Concentração Mínima Bactericida (CMB), também citadas por Rosário (2010) . A figura 2 foi obtida durante a técnica, a presença de coloração indica a existência de bactérias.

Para estas análises, empregaram-se seis diferentes cepas de bactérias, ATCC E.coli, SB 440/00 E.coli, SB457/00 E.coli, ATCC S. aureus, SB255/98 S.aureus e SB390/98 S.aureus, sendo todas provenientes do Laboratório de Bacteriologia (LABAC) da Universidade Federal de Santa Maria. Foram realizadas análises distintas, empregando-se água ou DMSO como diluentes. Todas as amostras foram testadas em triplicata para cada cepa.

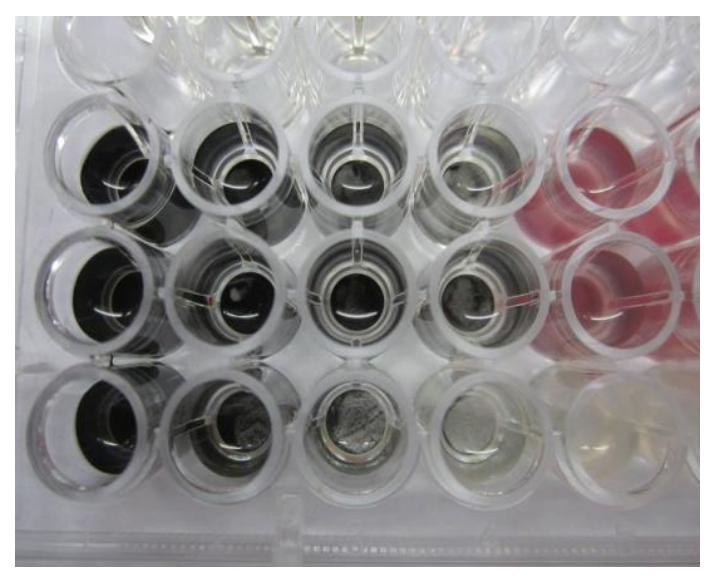

Figura 2- MIC carvão impregnado com prata. 


\section{RESULTADOS E DISCUSSÕES}

Através do experimento I, pode-se visualizar que a concentração ideal de prata na amostra de carvão era de aproximadamente $2,0 \%$, já que o diâmetro do halo inibitório tanto para esta quanto para a de concentração 5,0\% não variou muito, como pode ser observado na figura 3 .

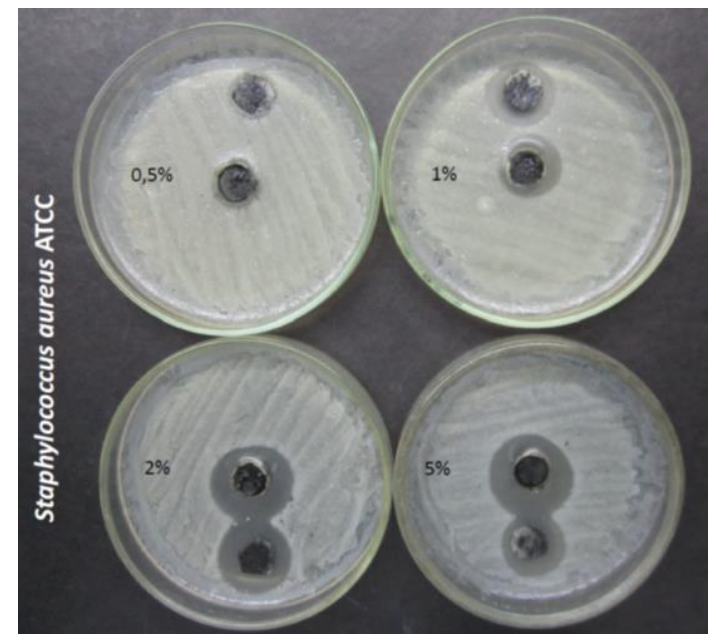

Figura 3- Disco-difusão em ágar.

Contudo, por se tratar de uma técnica qualitativa, os resultados da disco-difusão são muito influenciados pela espessura do ágar e pela profundidade do poço de inserção da amostra, assim, realizaram-se também técnicas quantitativas de concentração mínima inibitória e concentração mínima bactericida. A figura 4 traz a visualização de alguns dos resultados obtidos. A tabela 3 traz a síntese dos resultados obtidos para a amostra de carvão impregnado com prata.

Tabela 3- Resultados de CIM e CBM para prata.

\begin{tabular}{|l|c|c|c|c|}
\hline \multicolumn{1}{|c|}{ Amostras } & \multicolumn{2}{c|}{ Diluente: água } & \multicolumn{2}{c|}{ Diluente: DMSO } \\
\hline Prata em $\mu \mathrm{g} / \mathrm{mL}$ & CIM & CBM & CIM & CBM \\
\hline ATCC E.coli & $100 \mu \mathrm{g} / \mathrm{mL}$ & $100 \mu \mathrm{g} / \mathrm{mL}$ & $50 \mu \mathrm{g} / \mathrm{mL}$ & $50 \mu \mathrm{g} / \mathrm{mL}$ \\
\hline ATCC S.aureus & $50 \mu \mathrm{g} / \mathrm{mL}$ & $50 \mu \mathrm{g} / \mathrm{mL}$ & $50 \mu \mathrm{g} / \mathrm{mL}$ & $100 \mu \mathrm{g} / \mathrm{mL}$ \\
\hline SB440/00 E. coli & $200 \mu \mathrm{g} / \mathrm{mL}$ & $200 \mu \mathrm{g} / \mathrm{mL}$ & $25 \mu \mathrm{g} / \mathrm{mL}$ & $50 \mu \mathrm{g} / \mathrm{mL}$ \\
\hline SB390/98 S.aureus & $200 \mu \mathrm{g} / \mathrm{mL}$ & $400 \mu \mathrm{g} / \mathrm{mL}$ & $12,5 \mu \mathrm{g} / \mathrm{mL}$ & $50 \mu \mathrm{g} / \mathrm{mL}$ \\
\hline
\end{tabular}

Percebe-se que o DMSO funciona como um melhor diluente na técnica, possibilitando que concentrações menores de prata se dispersem e sejam suficientes para atuar como agente inibitório e bactericida. 


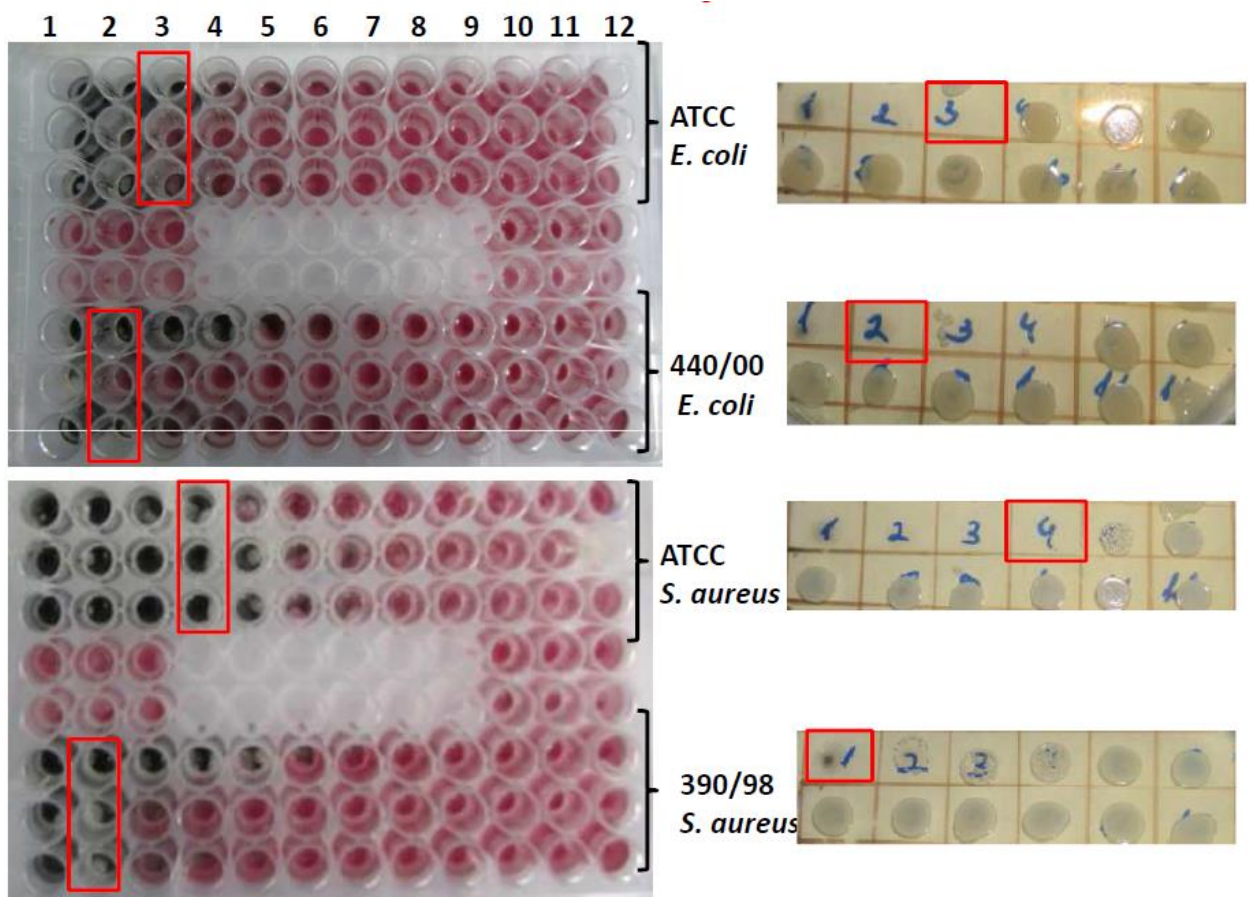

Figura 4- CMI (à esquerda) e CMB (à direita).

Por fim, através do experimento III, foram produzidas novas amostras de carvão impregnado com íons de prata, de zinco e de cobre. Por serem metais de conhecido efeito antimicrobiano, optou-se por avaliar a sua ação quando submetidos a tratamento térmico adicional, já que esta prática é citada inúmeras vezes nas publicações do gênero.

Sabendo-se que, dentre esses metais, a prata possui o maior efeito antimicrobiano, partiu-se de concentrações maiores de todas as amostras termicamente tratadas. A concentração inicial de metal empregada foi de $2000 \mu \mathrm{g} / \mathrm{mL}$, sendo sucessivamente diluída para 1/2. Contudo, os resultados obtidos demonstraram que mesmo conduzido em atmosfera inerte, o tratamento térmico reduziu ou até mesmo anulou a capacidade inibitória e a bactericida desses metais. $\mathrm{O}$ zinco e o cobre não tiveram ação bacteriostática nem bactericida. A prata não teve ação para ATTCC de E.coli, nem para a cepa 440/00, embora tenha apresentado CMI e CMB de 1000 $\mu \mathrm{g} / \mathrm{mL}$ para a ATCC de S. aureus e CMI de $1000 \mu \mathrm{g} / \mathrm{mL}$ para a cepa 390/98.

\section{CONCLUSÕES}

Através dos resultados obtidos, verifica-se que o carvão ativado é um suporte viável para a produção de um material antimicrobiano. Por ser um material usualmente empregado em tratamento de águas de consumo e em ambientes hospitalares, essa demanda torna a capacidade bactericida e a bacteriostática atrativas para esses fins. Em termos práticos, verificou-se que o DMSO atua como um melhor diluente para as técnicas de análise microbiológica e que embora 
citado em inúmeras referências, o tratamento térmico não se mostrou dequado para esse tipo de amostra.

\section{Referências}

ADHOUM, N.; MONSER,L. Removal of cyanide from aqueous solution using impregnated activated carbon. Chemical Engineering and Processing, v. 41, p.17-21, 2002.

KO, Tse-Tao. Method of fabricating product of activated carbon supporting silver. United States Patente. Patent n.US7,687,433 B2, mar.30,2010.

LI, B.; YU, S.; HWANG,J.Y.; SHI, S. Antibacterial vermiculite nano-material. Journal of Minerals \& Materials. Characaterization \& Enginneering, v.1, n.1, p. 61-68, 2002.

LI, Ch.Y,; WAN, Y.Z.; WANG, J.; WANG, Y.L.; JIANG, X.Q.; HAN, L.M. Carbon, v.36, p.61-65, 1998.

MORONES, J.R.; ELECHIGUERRA, J. L.; CAMACHO, A.; HOLT, K.; KOURI, J. B.; RAMÍREZ, J.T.; YACAMAN, M. J. The bactericidal effect of silver nanoparticles. Nanotechnology, v. 16, p. 2346-2353, 2005.

OYA, A.; KIMURA, M.; SUGO, T.; KATAKAI,A.; ABE, Y.; IIZUKA, T.; ,AKIYAMA,N.; LINARES-SOLANO, A.; SALINAS-MARTINEZ DE LECEA, C. , Carbon, v. 32, p.107-110, 1994.

OYA, A.; WAKAHARA, T.; YOSHIDA, S. Carbon, v.31, p.1243-1247,1993.

PARK, S; JANG, Y. Preparation and characterization of activated carbon fibers supported with silver metal for antibacterial behavior. Journal of Colloid Interface Science, v. 261, p. 238243, 2003.

ROSÁRIO, J.A., Obtenção de material antimicrobiano a partir de bentonita nacional tratada com prata. Tese de doutorado, Programa de Pós-Graduação em Engenharia Química, UFSC, 2010.

XAVIER, R.N.; TRAGHETTA, D. G.; OLIVERIA, C. M. R. Revista Brasileira de Ciências Ambientais, n.15, 2010. 